\title{
Choose What to Feel: Emotional Labour in Space of Classic Organizations and Virtual Collaborations
}

\author{
Kseniya Navazhylava \\ HEC Paris. 1, rue de la Liberation, 78350 Jouy-en-Josas, France \\ navazhylava.kseniya@hec.edu
}

\begin{abstract}
Technological progress infiltrated physical space of the organizations with cables, wires, monitors, landlines, blackberries, cameras, tablets up to the point, when we happened to witness the birth of the new, virtual, space. Here control and monitoring seems non-existent and unnecessary. But in fact, it is ingrained in the structure of the virtual space by means of technology which makes virtual reality real. Ingrained control triggers changes in series of organizational life phenomena. This work aims to look at the interplay between the use of technology and organizational space, as well as at the change that occurs in frameworks of emotional processes in organizations with growth of technological entanglement. Specifically, in the virtual space communication is due to the technology which compels people to choose between available sets of emotional cues. However, it enforces reducing, mitigating and channeling the emotions with the help of limited variants of expression - and, therefore, appraisal.
\end{abstract}

Keywords: Technology, space, virtuality, organizational behavior, emotional labour, appraisal, ingrained control, sociomateriality.

\section{Introduction}

21 th century opened a door into a new realm: the realm of unsteady space and organizations without a clear structure. Those types of organizations are known as collaborative networks - "networks of organizations that are largely autonomous, geographically distributed, and heterogeneous in terms of their: operating environment, culture, social capital and goals; nevertheless these organizations collaborate to better achieve common or compatible goals, and their interactions are supported by computer networks" [7]. Being the intersection of human agency and technology, collaborative networks materialized the claim of Bruno Latour to treat humans as things and materialize them [27]: all the objects without discrimination: humans, cats, roads, air, wires, screens, trees - became included into the imaginary and at the same time feasible network, in the form of light flashes, pixels and bits of code... At the same time, this kind of the environment requires attention to the human relationships as a base of social networks. However, the role of affect and emotion in individual and group processes has not been much recognized in attempts to understand the dynamics of collaborative research settings [4]. Emotions proved to 
have different impacts on the quality of e-learning [14]. Filipa Ferrada noted, that despite of significant benefits of the collaborations, namely innovations boosting and creating values, collaborative networks tend to fail [13]. One of the reasons she sees for that is the lack of specific systems to monitor the emotional state of the network. Hence, the research question, proposed in this paper, is: what is the way to manage the emotions in collaborative networks?

\section{Building vs. Constructing Space in Organizations}

Collaborative culture comprises all organizations' beliefs, knowledge, attitudes, and customs towards a supportive and positive behaviour to enhance the capabilities of others and the willingness to adapt for the benefit of all [35]. One of the primary requirements for the collaborative networks is effective communication, which is maintained by means of the technology in the virtual space. Being physically dispersed, but joined into the collaborative networks, people and organizations surrender to the illusion of total freedom of virtuality. But are the emotional processes in physical and virtual spaces really different? The answer to this question would play an important role in maintaining and improving the organizational culture and building the sustainable collaboration network.

From early organizational studies, architecture of buildings and other material issues is considered to have an impact on the behaviour of workers. Now this idea of technological "impact" has been deepened to the extent of inevitable "constitutive intertwining and reciprocal interdefinition of human and material agency" [42].

There are several approaches to conceptualize the notion of space in connection with organizations, from geographic space as location of business entities on the geographical map, to work space as individual area where one person works [40]. The concept of organizational space appears to be the most enveloping one, as it includes all types of influences of the environment on people within organizations. For the sake of preserving the purity of those concepts, the author finds it necessary to introduce a new nomination which is labour space. Labour space is defined as the intra-organizational physical emptiness at hand that may or may not be filled with objects, people, signs and senses.

There is no common view on the nature of space. Built space in the primary sense is nothing more that transformed matter, marking fixed things on maps [41]. Organizational space here is restricted to geographical boundaries of an organization. The other approach addresses space as a constant becoming [10]. Gilles Deleuze was the first to propose the concept of the virtual as a system of relations which creates actual spaces and possibilities, being modified by (here - by the worker) and constantly modifying (him or her) in its change.

When organizations started to use blackberries and iPhones, emails and internet chats, networks for data transfer and internet profiles of the co-workers, interactive maps of the departments to construct organizational space, they entered virtuality, where functions were unreadable and purposes were often obscure. Technology expanded the space into new horizons, those of collaborative networks as preordained parts of virtuality. 


\section{Emotions in Organizations: From Downplay to Appraisal}

Newly constructed virtual organizational space of collaborative networks brought new challenges to understanding of emotions in the life of institutions. Although even now scientific management concepts, representing emotion as irrational, personal, and feminine [30], [43], sometimes find support within organizations, organizational studies moved to encompassing positive influence of emotions on performance on different levels [12]. The theories of emotion are still much divided, but emotion is no longer treated as a poor relation in the philosophy of mind [11]. By contrast, authors continue to argue for the importance of including analyses of emotional and unconscious processes in the study of institutional work [44].

$21^{\text {th }}$ century brought along an attempt to reconcile the theory of emotion with technological invasion. Although studies had been primarily based on cognitive models, emotions were also argued to be important drivers of behaviors. As minds are nor purely cognitive nor purely emotional - they are both and even more [28], emotions had to be concerned in management studies. Affects proved to be connected to the activity of different brain areas and amygdala [1] and therefore inevitable. Human brain is able to sense fear even before one can think of it [20]. So, treating the emotions and affects presented a new challenge for the managers. In the virtual space of the collaborative networks management of affects became one of the crucial questions. It occurred, that mere environmental possibility to communicate does not mean people would involve in Human-Computer networks [12], before they start to offer warmth, trust and affectivity of natural relationship. As a consequence, researchers claimed to consider not only user preferences, but also users emotionallaffective states [33]. Beaudry and Pinsonneault [3] showed that emotions felt by users early in the implementation of a new IT have important effects on IT use. The attempts to stop ignoring emotions for the sake of the society health materialized in developing the collaborative system approach to create the networks for professionally active aging [8], and emotion-aware strategies to detect learner's affective state [13]. Some authors propose to use standard as cameras to capture subjective, unconscious motor behaviour which would encourage student's positive attitude towards learning, assure student's emotional safety and foster their metacognitive and meta-affective skills [14].

Hillary Anger Elfenbein's Integrated Interpersonal Process Framework for emotion in organizations [12] opens the "black box" of emotions experience. It encompasses both process and structural understandings of the emotions, by breaking the path between stimuli and emotional expression into several, cognitive and psychological, steps. The paths for the adressant and adresat of the emotion are linked into interpersonal roundabout, where the emotional cue of one functions as the emotional stimuli of the other. Coupled together with the appraisal theory of emotions, this framework casts some light on interesting new phenomena in the life of virtual organizations that hadn't been present before, like reducing, mitigating and channeling the emotions with the help of limited variants of its appraisals. 


\section{Emotions in Three Types of Spatio-technological Forms of Organizations}

There are three types of organizational spaces - integrated, limited (cubicle) and virtual - that are considered within this study. Every type has its own intensity of technological infiltration and emotion control on the workplace. Development of the labour space of the organization follows its complexity, which the author witnessed on the example of the newspaper (firm B.) in Belarus where she had been working for 10 years. This example is offered as an illustration for the interplay of the labour space and emotional labour management in one given organization (Table 1).

Table 1. The interplay of the labour space and emotional labour management in one given organization

\begin{tabular}{|c|c|c|c|}
\hline $\begin{array}{l}\text { Types of } \\
\text { labour } \\
\text { space }\end{array}$ & $\begin{array}{l}\text {-big common room, } \\
\text { the rows of desks not } \\
\text { clustered r or } \\
\text { differentiated r by } \\
\text { belonging to a certain } \\
\text { group. }\end{array}$ & $\begin{array}{l}\text {-cubicle spaces: more privacy }+ \\
\text { lag between emotional experience } \\
\text { of one worker and emotional } \\
\text { registration of the other. }\end{array}$ & $\begin{array}{lr}\text {-geographical } & \\
\text { dispersion: } & \\
\text { technological } & \text { border } \\
\text { between } \quad \text { worker's } \\
\text { emotional experience } \\
\text { and other's registration. }\end{array}$ \\
\hline $\begin{array}{l}\text { Function of } \\
\text { the } \\
\text { technology }\end{array}$ & $\begin{array}{l}\text {-strictly functional; } \\
\text { computers as printing } \\
\text { machines, mobile } \\
\text { phones not published } \\
\text { on the visit cards, the } \\
\text { exchange of } \\
\text { information occurred } \\
\text { in a simple meeting in } \\
\text { a face to face }\end{array}$ & $\begin{array}{l}\text {-communicational: internal } \\
\text { network to exchange the files, } \\
\text { inside ICQ messenger to reach the } \\
\text { administrators or colleagues. } \\
\text {-monitoring: surveillance by } \\
\text { closed-circuit television cameras } \\
\text { (CCTV) (would be impossible in } \\
\text { the countries with a different legal } \\
\text { system - Author); calls recording } \\
\text { system }\end{array}$ & $\begin{array}{l}\text {-constructional and } \\
\text { absolutely (?) free: ICQ, } \\
\text { Skype, internet } \\
\text { browsers, software for } \\
\text { editing the websites } \\
\text { installed on their } \\
\text { computers, contacts } \\
\text { with help of different } \\
\text { devices networks as } \\
\text {-social netriatem } \\
\text { monitoring system } \\
\text {-ISPs able to track } \\
\text { activities. }\end{array}$ \\
\hline $\begin{array}{l}\text { Emotional } \\
\text { labour } \\
\text { peculiarities }\end{array}$ & $\begin{array}{l}\text {-regulation of displays } \\
\text { of emotions instant } \\
\text { and immediate. } \\
\text {-constant emotion } \\
\text { suppression } \\
\text {-limited private places } \\
\text { (toilet, closet or server } \\
\text { room). } \\
\text {-control implemented } \\
\text { by one or more } \\
\text { supervisors } \\
\text { overlooking the rows } \\
\text { of desks modern } \\
\text { Panopticon [17] }\end{array}$ & $\begin{array}{l}\text {-fewer possibilities to observe the } \\
\text { behaviour of the workers } \\
\text {-freedom to choose how and when } \\
\text { to express the emotional cues to } \\
\text { the others (via natural } \\
\text { communication channels, as the } \\
\text { space of the cubicles is not totally } \\
\text { divided from the rest of the equip, } \\
\text { or with the means of technology). } \\
\text {-still expected to suppress their } \\
\text { emotional displays to meet the } \\
\text { feeling rules of the company [37], } \\
\text { [11] }\end{array}$ & $\begin{array}{l}\text {-possibilities of } \\
\text { monitoring ingrained } \\
\text { into the technology } \\
\text {-limited number of } \\
\text { emotional cues }\end{array}$ \\
\hline
\end{tabular}

As a start-up in mid-90s, B. used a bullpen open office system of labour space, where the use of technology was limited to the mere functionalist tool. Hence, emotional framework presented by Hillary Elfenbein existed in an unchanged form: stimuli$>$ motional registration->emotional experience->emotional expression->expressive cues 
[12]. Automatic components were controlled to some possible extent under the omnipresent gaze to produce an emotional cue. This cue served directly as stimuli to the other workers: for instance, the fruitless phone talk with the expert caused internal rush that is appraised as anger, experienced as the difference in the emotional state, and displayed due to the emotional style of the adresant (for instance, throwing the phone receiver on the table). This type of behaviour serves as a stimuli for the colleagues to react emotionally. In cubicles the link between emotional displays of one employee and emotional registration of the other became way weaker. In recent past, with collaborative networks of people who could work from their own locations without being observed by the supervisors, restrictions as for the software or modes of information exchange became impossible. However, virtual labour space with its deceptive freedom appeared to have the opportunity of absolute control ingrained in it (see Table 1). This control seemed not to encompass the field of emotional labour. Although free-lancers were expected to share corporate culture with the company they work for, it was no longer the supervisor responsible for it. It was material agency of technology that remained the ultimate source of constructing the labour space [6], [26]. Being functional to the communication within the organization and closely connected to the type of organizational space, technology helps to objectify the emotions and appraise them in a different way [19].

As a means of emotional control, technology gives a way to conceal inappropriate emotions because of changing direct communication between workers to indirect. The lag, which exists between emotional stimuli and display of emotion, gives an opportunity to suppress and even totally change emotional cues. Surveillance over emotions in collaborative network is no longer included, and it seems that displaying the emotions is left on behalf of the employees. This situation is quite novel, as a vast body of research shows omnipresence of emotional labour. It is not restricted just to the low-paid jobs, but also exists in the work of doctors, top-managers and academic professors [5], [30], [34], [2], [15], [22]. Accordingly, although workplace is an inevitable cauldron of repressed thoughts, fantasies and desires [24], [18], the behaviour of the personnel is put under ,feeling rules” [38], [21]. Technology and geographical dispersion break the framework by giving the worker opportunity not to suppress bodily display, but to program the virtual self-reaction according to the corporate rules.

However, the ways to display emotions virtual space are limited. To express emotions, users invented special symbols - emoticons, which shortly started to prevail in communication. The choice of emoticons is restricted to less than dozen variants available. Having to choose the appropriate artificial cue from limited categories of emoticons, users have to comprehend the emotion and analyze it. Thus they move the priority in the emotional process to its cognitive phase, where they direct the emotion into proposed channel. As the appraisal theory states, "we feel sorry because we cry, angry because we strike, afraid because we tremble, and [it is] not that we cry, strike, or tremble, because we are sorry, angry, or fearful, as the case may be" [23]... It was proved with the experiment that people are incapable to differentiate emotions in lack of context. Cannon claimed back in 1929 [9], that the visceral reactions characteristic 
of distinct emotions such as fear and anger are identical, and so these reactions cannot be what allow us to tell emotions apart. The experiment performed by Stanley Schacter and Jerome Singer [37] bolstered this observation. Being injected with epinephrine, a stimulant of the sympathetic system, people tended to interpret the arousal they experienced either as anger or as euphoria, depending on the type of situation they found themselves in.

So, it is appraisal what predicts what is felt [2]. Technology channels the emotional feeling and changes the recognition of the emotion on the stage of primary appraisal [26] by proposing limited ways of its further displaying. Thereby seeming freedom of virtual space leaves us with a big question whether it does not present just another variant of control ingrained in it - this time, with no limits.

\section{Conclusions}

Recent organizational studies show how organization structures, controls and prescribes the emotions. But in new types of labour spaces which are provided by the collaborative networks, the nature of control is different. While in integrated space of bullpen offices the control over displays of emotions is instant, immediate and subjectivised (in the figure of supervisor), infiltration of technology into the structure of labour space changes the framework of emotion in organization. First, it creates the lag between the registration and experiencing the emotion and displaying the emotional cue, creating the agency component in the question whether to show or not the registered emotion and through which channel. It dissolves the interpersonal link between the emotional cue of the adressant and adressat in the organizational communication, as the cues might transfer just the appropriate emotions. In the virtual organizational space of collaborative networks the artificial component in the framework makes the choice of emotional cue more pronounced and limited to the number of proposed emoticons, channeling the appraisal of emotion and thus the emotional experience on the stage of primary appraisal. This theoretical proposition opens new horizons for monitoring and managing the affects in the collaborative networks. Finding means for supervising the emotions in these kinds of networks and developing the emotions-oriented system is extremely important for the health of the community [13]. As well, it would give the possibility to create effectively the affective network based on dialog and supportive and positive behaviour, which is key for to partnership renewal [36], [35]. Also it could play the crucial role in building of trust in the collaborative networks, as Istvan Mezgar proposes that demonstration of interest and commitments, being polite and positive are vital for building connections in the virtual space [32]. Therefore, the author claims for more research on emotions appraisal in collaborative network setting. Propositions, presented in the paper, are empirically testable with the help of both qualitative and quantitative tools. Experimental study would test whether use of the emoticons really changes the emotion reported by the collaborators, while comparative case-study would allow clarifying the process framework of the emotions in the collaborative networks. 


\section{References}

1. Afzal, S., Robinson, P.A.: Study of Affect in Intelligent Tutoring. In: Proceedings of the Workshop on Modelling and Scaffolding Affective Experiences to Impact Learning, International Conference on Artificial Intelligence in Education, Los Angeles (2007)

2. Ashforth, B.E., Humphrey, R.H.: Emotion in the Workplace: A Reappraisal. Human Relations 48(2), 97-125 (1995)

3. Beaudry, A., Pinsonneault, A.: Understanding User Responses to Information Technology: A Coping Model of User Adaptation. MIS Quarterly 29, 493-524 (2005)

4. Beesley, L.: The Management of Emotion in Collaborative Tourism Research Settings. Tourism Management 26(2), 261-275 (2005)

5. Brown, A.D.: Narcissism, Identity, and Legitimacy. Academy of Management Review 22, 643-686 (1997)

6. Callon, M.: Society in the Making: The Study of Technology as a Tool for Sociological Analysis. In: Bijker, W.E., Hughes, T.P., Pinch, T.J. (eds.) The Social Construction of Technical Systems: New Directions in the Sociology and History of Technology, pp. 83-103. MIT Press, Cambridge (1987)

7. Camarinha-Matos, L.M., Afsarmanesh, H.: Collaborative Networks: Value Creation in a Knowledge Society. In: Wang, K., et al. (eds.) Knowledge Enterprise: Intelligent Strategies in Product Design, Manufacturing and Management, PROLAMAT 2006. IFIP AICT, vol. 207, pp. 26-40. Springer, New York (2006)

8. Camarinha-Matos, L.M., Afsarmanesh, H.: Collaborative mechanisms for a new perspective on active ageing. In: Proceedings of DEST 2009 - 3rd IEEE Int. Conference on Digital Ecosystems and Technologies, Istanbul, Turkey, June 1-3 (2009)

9. Cannon, W.: Bodily Changes in Pain, Hunger, Fear and Rage. Appleton, New York (1929)

10. Deleuze, G.: Spinoza: Practical Philosophy. City Lights Books, San Fransisco (1988)

11. Goldie, P.: The Emotions: A Philosophical Exploration. Clarendon Press, Oxford (2000)

12. Elfenbein, H.A.: Chapter 7: Emotion in Organizations. The Academy of Management Annals 1, 315-386 (2007)

13. Ferrada, F., Camarinha-Matos, L.M.: Emotions in Collaborative Networks: A Monitoring System. In: Camarinha-Matos, L.M., Shahamatnia, E., Nunes, G. (eds.) DoCEIS 2012. IFIP AICT, vol. 372, pp. 9-20. Springer, Heidelberg (2012)

14. Feidakis, M.: Emotional scaffolding with respect to time factors in Networking Collaborative Learning Environments. eLC Research Paper Series 3, 26-36 (2011)

15. Fineman, S.: Emotion and Organizing. In: Clegg, S.R., Hardy, C., Nord, W.R. (eds.) Handbook of Organization Studies, pp. 543-564. Sage Publications, London (1996)

16. Fineman, S.: Emotion in Organisations. Sage Publications, London (2000)

17. Foucault, M.: Discipline and Punish: The Birth of the Prison. Random House, New York (1975)

18. Gabriel, Y.: Organisations in Depth: The Psychoanalysis of Organizations. Sage Publications, London (1999)

19. Gagliardi, P.: Exploring the Aesthetic Side of Organizational Life. Studying Organization: Theory \& Method (1999)

20. Goleman, D.: Emotional Intelligence. Bantam Books, New York (1995)

21. Hochschild, A.: The Managed Heart. University of California Press, Berkeley (1983)

22. Jones, L.: Smiling Lessons and Service with a Scowl in Greenland. The Guardian (October 23, 1999), Cited in Fineman (2000) op. cit.

23. James, W.: What is an Emotion? Mind 9, 188-205 (1884) 
24. Jacques, E.: Why the Psychoanalytic Approach to Organisations is Dysfunctional. Human Relations 48(4), 343-349 (1995)

25. Lacan, J.: The Four Fundamental Concepts of Psychoanalysis. Hogarth Press, London (1977)

26. Latour, B.: Technology is Society Made Durable. In: Law, J. (ed.) A Sociology of Monsters: Essays on Power, Technology and Domination. Sociological Review Monograph, pp. 103-131. Routledge, London (1991)

27. Latour, B.: Reassembling the Social: An Introduction to Actor-Network Theory. Oxford University Press, Oxford (2005)

28. LeDoux, J.E.: Emotion Circuits in the Brain. Annual Review of Neuroscience 23, 155-184 (2000)

29. LeDoux, J.E.: The Emotional Brain: The Mysterious Underpinnings of Emotional Life. Simon \& Schuster, New York (1996)

30. Leidner, R.: Emotional Labor in Service Work. The ANNALS of the American Academy of Political and Social Science 561, 181-195 (1999)

31. Mumby, D.K., Putnam, L.L.: The Politics of Emotion: A Feminist Reading of Bounded Rationality. Academy of Management Review 17, 465-486 (1992)

32. Mezgár, I.: Trust Building in Virtual Communities. In: Camarinha-Matos, L.M., Paraskakis, I., Afsarmanesh, H. (eds.) PRO-VE 2009. IFIP AICT, vol. 307, pp. 393-400. Springer, Heidelberg (2009)

33. Picard, R.: Affective Computing. MIT Press, Cambridge (1997)

34. Pierce, J.L.: Emotional Labor Among Paralegals. Annals of the American Academy of Political and Social Science 561, 127-142 (1999)

35. Romero, D., Galeano, N., Molina, A.: Readiness for Collaboration Assessment Approach in Collaborative Networked Organisations. In: Azevedo, A. (ed.) Innovation in Manufacturing Networks. IFIP, vol. 266, pp. 47-56. Springer, Boston (2008)

36. Ståhle, P., Laento, K.: Strategic Partnership: Key to Continuous Renewal. In: WSOY, Economy, Helsinki (2000)

37. Schacter, S., Singer, J.: Cognitive, Social and Physiological Determinants of Emotional States. Psychological Review 69, 379-399 (1962)

38. Scheff, T.J.: Microsociology: Discourse, Emotion, and Social Structure. University of Chicago Press, Chicago (1990)

39. Scherer, K.R., Shorr, A., Johnstone, T. (eds.): Appraisal Processes in Emotion: Theory, Methods, Research. Oxford University Press, Canary (2001)

40. Smith, P., Kearny, L.: Creating Workplaces Where People Can Think. Jossey-Bass, San Francisco (1994)

41. Straus, E.: The Primary World of Senses: A Vindication of Sensory Experience (1963)

42. Suchman, L.: Plans and Situated Actions: The Problem of Human-Machine Communication. Cambridge University Press, New York (1987)

43. Taylor, F.W.: The Principles of Scientific Management. Harper, New York (1911)

44. Voronov, M., Wince, R.: Integrating Emotions into the Analysis of Institutional Work. Academy of Management Review 37(1), 58-81 (2012) 